https://doi.org/10.4314/jpb.v17i1.8

Vol. 17 no. 1, pp. 44-51 (March 2020)

http://ajol.info/index.php/jpb

\section{Journal of \\ PHARMACY AND \\ BIORESOURCES}

\title{
Impact of training of primary healthcare workers on integrated community case management of childhood illnesses in North-West district of Benue State, Nigeria
}

\author{
Uya John ABUA ${ }^{1 *}$, Terhemen Joseph IGBUDU ${ }^{2}$, Livinus EGWUDA ${ }^{2}$ and Gberndyer \\ Jacob YAAKUGH ${ }^{3}$
}

${ }^{I}$ Department of Pharmacology and Therapeutics, College of Health Sciences, Benue State University, Makurdi. Nigeria. $\quad{ }^{2}$ Department of Family Medicine, Benue State University Teaching Hospital, Makurdi. Nigeria.

${ }^{3}$ Department of Medical Microbiology, College of Health Sciences, Benue State University, Makurdi. Nigeria.

Received $12^{\text {th }}$ September 2019; Accepted $31^{\text {st }}$ January 2020

\begin{abstract}
The World Health Organization and United Nations Children's Fund has introduced Integrated Community Case Management of childhood illness (ICCM) in order to train health workers at community level on how to treat children below 5 years who have pneumonia, diarrhoea and malaria. Since Primary Health Care workers in Benue State are actively involved in caring for sick children at community level, there is every need for them to be trained on ICCM. The objective of this study is to find out if training of primary health care workers in North-West district of Benue State can improve their knowledge on ICCM. The study was carried out in Benue North-west where Gboko Local government was randomly selected out of seven local governments. Health Officers' in-charge of 38 Primary Health Care Clinics were selected for the study and were trained based on our adapted ICCM training manual. The Pre and Post training assessment test for this study was designed based on the training manual. A paired sample t-test was conducted to find out if there were any significant difference in the knowledge of primary health care workers before and after receiving training. There was significant difference in the pre training scores ( $\overline{x_{1}}=136.684, S_{1}=37.370$ ) and post-training scores $\left(\overline{x_{2}}=177.895, S_{2}=14.469\right)$ at $(\mathrm{t}=6.783, \mathrm{P}=0.000)$. This result strongly indicates that the teaching intervention has improved the knowledge of the Primary Health Care workers on ICCM in Gboko Local Government.
\end{abstract}

Keywords: ICCM; Pneumonia; Malaria; Diarrhoea

\section{INTRODUCTION}

It has been observed that community health workers appropriately trained, supervised, and supported with essential medicine and basic equipment can identify and correctly treat most children who have malaria, diarrhoea and pneumonia [1,2]. The World
Health Organization (WHO) and the United Nations Children's Fund (UNICEF) has issued a joint statement supporting the training of health workers at community level on Integrated Community Case Management (ICCM) of childhood illnesses in order to improve the optimal treatment of children

*Correspondence. E-mail: johnabua@ymail.com Tel: +234-7031286876

ISSN 0189-8442 (c) ) BY-NC

2020 Published by Faculty of Pharmaceutical Sciences, University of Jos, Nigeria. Under Creative Commons Attribution-NonCommercial 4.0 International License. https://creativecommons.org/licenses/by-nc/4.0/ 
below 5 years who have the conditions mentioned above. As part of the ICCM strategy, front-line health workers are trained, supplied with basic equipment and essential drugs to treat children for both diarrheal and pneumonia as well as malaria using oral rehydration salt solution (ORS) and Zinc, Oral antibiotic, Malaria Rapid Diagnostic Test (RDT) kits and Artemisinin-based Combination Therapy (ACT) [3].

Malaria is an infectious disease caused by parasites of the genus plasmodium. The four identified species of parasites causing human malaria are: Plasmodium falciparum, $P$. vivax, $P$. ovale and $P$. malariae. In Nigeria, about $98 \%$ of all cases of malaria are due to Plasmodium falciparum. It is transmitted from the bites of an infected female Anopheles mosquito to man. It has been reported that in Nigeria, malaria counts for $60 \%$ of out-patients visit and $30 \%$ hospitalization among children under 5 years, Malaria is also common in pregnant women especially primigravidae [4] Malaria related deaths account for up to $11 \%$ of maternal mortality, $25 \%$ infant mortality and $20 \%$ in children below five years resulting in about 300,000 childhood death annually [4].

Diarrhoea is one of the major causes of morbidity and mortality especially in children. The diarrhoea prevalence rate in Nigeria is $18.8 \%$ and is one of the worst in sub-Sahara Africa. It accounts for over $16 \%$ of child deaths in Nigeria and an estimated 150,000 deaths mainly amongst children under five occur annually due to diarrhoea as a result of poor sanitation and poor hygiene practices $[5,6]$.

Acute Respiratory Infections (ARI) globally accounts for approximately 4 to 5 million deaths annually $[7,8]$. More than two third of the global burden from ARI related deaths occur in Africa [9]. It has been reported that every child has about 5 to 6 episodes of ARI in a year accounting for about $30-50 \%$ of the total paediatric outpatients' visits $[10,11]$. Data from National Demographic Health
Survey 2013 reported the prevalence of ARI in Nigeria to be about $2 \%$ [12].

In Nigeria, Primary Health Care (PHC) is one of the grass-root management approach to providing health care services to communities. PHC are staffed by senior Community Health Officers (CHO), Community Health Extension Workers (CHEW), Junior Community Health Extension Workers (JCHEW), Nurses, Midwives, Medical Laboratory technicians and pharmacy assistants. The services provided at these PHCs include prevention and treatment of common communicable diseases, immunization, maternal and child health services, family planning, public health education, environmental health and the collection of data on health and health related events. A greater population of the inhabitants of Benue individuals including children lives in the rural areas, and are attended to by these community health workers when they are sick. PHC in Nigeria is the entry point of the health care system. Cases that cannot be treated at this level are referred to the nearest secondary health care such as General Hospitals or tertiary health care/Teaching Hospitals $[4,13]$.

Since primary health care workers in Benue State are actively involved in caring for sick children at community level, there is every need for them to be fully trained on ICCM. The objective of this study is to find out if training of primary health care workers in North-west district of Benue State on ICCM can improve their knowledge on integrated management of childhood illnesses. This study is therefore designed not only for the training but also for assessment of health care providers at primary health care level. Since this study is being carried out in the study location for the first time, it will better inform the appropriate authorities on whether to domesticate ICCM in Benue State or not. 


\section{METHOD}

Study area. Benue State is located in the middle -belt region of Nigeria. The state is divided into 3 zones or geopolitical zones or district as follows: Benue North-East (Zone A) with seven Local Government Areas, Benue North-West (Zone B) also with seven Local Government Areas and Benue South (Zone C) with nine Local Government Areas. This study was carried out in Benue North-west (Zone B) which is made up of the following Local Governments: Guma, Buruku, Gboko, GwerEast, Gwer-West, Makurdi and Tarka. One local government in Zone B (Gboko LGA) was randomly selected out of the seven local governments for this study.

Gboko Local government has a population projection in 2016 of 242,476 males and 243,114 females; making up a total population projection of 485,590 . Out of this, about $18.4 \%$ of the total population in Gboko LGA is made up of children below 5 years [14]. Apart from Gboko Town which is a semiurban settlement, the rest of the people in Gboko LGA reside in rural areas. Preliminary investigations show that there are about 44 primary health care facilities in Gboko LGA however only 38 PHC located in the LGA participated in this study. There are about 218 health workers working in the 38 primary health care clinics as follows: 1 (0.5\%) Public Health Graduate, 5 (2.3\%) Senior Community Health Officers, 103 (47.2\%) Community Health Extension Workers, 55 (25.2\%) Junior Community Health Extension Workers, 27 (12.4\%) Nurses, 8 (3.7\%) Midwives, 18 (8.2\%) Laboratory Assistants or Technicians, $1(0.5 \%)$ Pharmacy assistant.

Since it was difficult to train all the 218 health workers in Gboko LGA, officers in charge (if absent, their assistants) in all the 38 health care facilities in Gboko LGA were invited to Gboko town for the training /assessment exercise. The selection of officers in charge or their assistants was based on the assumption that on receiving training, they will step down and pass the knowledge to other health workers in their clinics.

The study. The training manual for this study "Integrated Community Case Management of Childhood Illnesses in Benue State" was adapted from WHO and UNICEF Handbook "Caring for the sick Child in the community, a training course for Community Health Worker" [15]. Other documents used were: National Malaria Strategic Plan 2014- 2020 [4], Federal Ministry of Health Module 2 Case Management of Malaria at the Primary Healthcare Centre, Trainee Content [16], National Guideline for Diagnosis and Treatment of Malaria [17], MacGill Markus [18]; Khan Waqas and Sellen Daniel [19]. The pre and post training assessment test for this study was designed based on the above adapted training manual.

Ethical Clearance for this study (Ref. no. BSUTH/MKD/HREC/2O13B/2017/0016) was obtained from Benue State University Teaching Hospital, Makurdi.

The selected officers were given a three days intensive training by the authors in form of lectures, explanations, practical demonstration by trainers in the presence of trainees, practical demonstration by trainees in the presence of trainers, question and answer sessions, group discussion, performance of RDT by participants on each other and sharing of relevant experiences and encounters by trainees and trainers on the following:

1. Malaria and its management:

a) What is malaria, its transmission, prevention, signs and symptoms?

b) How to perform RDT and the importance of parasitological diagnosis in the management of malaria.

c) How to treat confirmed simple uncomplicated malaria with different ACT drugs.

d) How to recognise or diagnose severe malaria in children, pre-referral treatment with artesunate suppositories and subsequent referral.

2. How to recognise or diagnose the following danger signs of severe illnesses in children, first aid and or pre-referral treatment and subsequent referral.

a) Convulsions or fits 
b) Not able to drink when giving a drink or breast feed

c) Severe vomiting or vomiting everything

d) Unusually sleepy, drowsiness or unconsciousness

e) Severe anaemia demonstrable by very pale nail beds, palms, conjunctiva or tongue

f) Severe dehydration shown by sunken eyes, skin turgor and dryness of the buccal mucous membrane and degree of thirst.

g) Difficulty in breathing with intercostal, subcostal recession (chest in-drawing)

h) Stiff neck (sign of meningitis)

i) Tender swollen behind the ear (mastoiditis)

j) Visible severe wasting and oedema of both feet/ ankles (severe malnutrition)

3. Respiratory tract infection and fever in Children

a) How to diagnose acute respiratory tract infection with cough by counting respiratory rates and treating those with rates above the normal cut off for age and administration of antibiotics (oral amoxicillin).

b) How to diagnose severe pneumonia in children with cough and difficulty in breathing by counting the respiratory rates and observing the chest for chest-in drawing, initiating management and subsequent referral.

c) How to carry out system by system examination/diagnosis of illnesses in children with fever including treatment or first aid measures and possible referral as the case may be.

4. Diarrhoea and its management in children

a) How to diagnose and treat children with acute watery diarrhoea with ORT and Zinc

b) How to prepare and give pre-packed ORS solution to children with diarrhoea.

c) How to prepare and give salt, sugar and water solution to children with diarrhoea in absence of pre-packed ORS

d) How to diagnose and refer children with moderate to severe dehydration due to diarrhoea who are restless or irritable by observing presence or absence of sunken eyeballs, abdominal skin turgor, and degree of thirst.

e) How to diagnose and refer children with bloody, persistent and chronic diarrhoea

f) How to prevent diarrhoea and the use of Zinc in the treatment of diarrhoea.

5. How to diagnose and treat other childhood illnesses such as:

a) Treat acute ear infections with ear pain and discharge with oral amoxicillin and paracetamol

b) Treat skin rashes and or abscess due to bacterial infections with antibiotics (oral amoxicillin).

c) Treat children with mild to moderate anaemia due to malaria, worm infestation or nutritional causes as follows: i. If test for malaria is positive give anti malaria drugs (ACT).

ii. If test for malaria is negative deworm the child (above one year old) with Mebendazole

iii. Give multivitamin preparations containing iron and counsel for good nutrition in both (i and ii) above

6. Others

a) How to identify and quickly refer cases of suspected treatment failures

b) Teach child care givers how to give drugs to their children at home

c) How to improve patients' adherence to treatment

d) How to improve management and storage of medicines or drugs in a health facility

The designed pre and post training assessment test for primary health care workers based on the training manual was used to observe if there were any significant difference in their knowledge before and after receiving training

\section{RESULTS}

The pre training assessment scores and post training assessment scores from our study was classified or grouped into topics as follows:-

a) 90 pre training assessment questions and 90 post training assessment question where set for malaria and its management

b) 62 pre and post training assessment questions each on how to recognize severe illness and cases of treatment failure in children, first aid management and referral.

c) 27 pre and post training assessment question each for management of acute respiratory tract infections and other childhood illnesses.

d) 24 pre and post training assessment questions each for diarrhea and its management especially in children.

e) This makes up to a total of 203 pre training assessment questions and 203 post training assessment questions for Gboko study. Each participant was to answer each of the above question by indicating TRUE if the question or statement was true and FALSE if the question or statement was false.

The formula for t-test for the differences of two means

$$
t=\frac{\overline{x_{1}}-\overline{x_{2}}}{\sigma \sqrt{\left(\frac{1}{N_{1}}+\frac{1}{N_{2}}\right)}}
$$


Where $\sigma=\sqrt{\left(\frac{N_{1} S_{1}^{2}+N_{2} S_{2}^{2}}{N_{1}+N_{2}-2}\right)}$

$N_{1}+N_{2}-2=$ degree of freedom; $\overline{x_{1}}=$ Pretraining Mean; $\quad S_{1}=$ Pre-training standard deviation; $\overline{x_{2}}=$ Post-training Mean; $S_{2}=$ Posttraining standard deviation

The formula for t-test for the differences of two means also the \% mean response was used to compare statistically the pre training assessment scores with the post training assessment scores in order to see if there is any significant difference in the knowledge of the primary health care workers before and after receiving training.

Biodata of participants. The biodata of participants and topic by topic analysis of result and our findings from Gboko local government area are presented in Tables 1 and 2. The biodata of 38 primary health care workers from Gboko LGA who participated in the study is as follows: 36 (94.7\%) of participants were officers in charge, only 2 (5.3\%) were Assistant Officers. On educational qualifications one participant (2.6\%) had a B.Sc. degree in Public Health while $4(10.5 \%)$ had both Nursing and Midwifery certificate and one had a nursing certificate only which makes up a total of 6 $(15.7 \%)$. The remaining $84.3 \%$ was made up of $2(5.3 \%)$ Senior Community Health Workers, $26(68.4 \%)$ Community Health Extension Workers and $4(10.5 \%)$ were Junior Community Health Extension Workers. Apart from the junior community health extension workers, about $34(89.5 \%)$ of participants were well experienced community Health Workers.

On how to communicate, about 28 $(73.7 \%)$ could communicate or read and write in English and Tiv;(Tiv is the main ethnic language in Gboko LGA) and only 10 (26.3\%) could read and write in English only. 14 $(36.8 \%)$ participants were males and 24 $(63.2 \%)$ were females. $32(86.8 \%)$ participants were adults within the ages of $30-59$ and only $5(13.2 \%)$ were adolescents $(20-29$ years old). It was also observed that $34(89.5 \%)$ of participants were married, $2(5.3 \%)$ were not married and $2(5.3 \%)$ were widowed. From the bio- data, 30 (79\%) of participants had at least one or more children.

From the Bio-data, it was observed that most of the participants were experienced adults who were married and have children and as such may have come across the disease condition affecting children discussed in their training.

Mean \% response. From the pre and post training Mean percentage $(\%)$ response (table 1), it was observed that training of Community Health Workers from Gboko LGA had improved their knowledge on Malaria and its management from 71 to $90 \%$, Acute Respiratory Tract infection and other childhood illnesses from 57 to $79 \%$, Diarrhea and its management from 61 to $83 \%$, on how to recognize severe illnesses and cases of treatment failure in children, first aid management and referral, from 69 to $90 \%$, and on the overall performance from Gboko LGA there was improvement in Health Workers knowledge from 67 to $88 \%$, (Table 1)

Paired Sample t-test. A paired sample t-test (table 1 and 2) was conducted to find out if there were any significant difference in the knowledge of primary health care workers on all topics indicated above before and after receiving training. There was a significant difference on all topics in the pre-training scores and post -training scores in Gboko LGA as follows:

a. Malaria and its management: There were significant difference in pre - training scores $\left(\bar{x}_{1}=63.816, S_{1}=\right.$ $15.901)$ and post- training scores $\left(\overline{x_{2}}=80.895, S_{2}=\right.$ $8.754)$ at $(\mathrm{t}=-5.800, \mathrm{P}=0.000)$.

b. How to recognize severe illnesses in children, first aid management and referral: There were significant difference in the pre - training scores $\left(\bar{x}_{1}=42.868\right.$, $\left.S_{1}=13.346\right)$ and post training scores $\left(\overline{x_{2}}=55.842\right.$, $\left.S_{2}=4.396\right)$ at $(\mathrm{t}=5.692, \mathrm{P}=0.000)$. 
c. Management of Acute Respiratory Tract Infection and other childhood illnesses: There were significant difference in the pre - training scores $\left(\overline{x_{1}}=15.368\right.$, $\left.S_{1}=6.491\right)$ and post training scores $\left(\overline{x_{2}}=21.237\right.$, $\left.S_{2}=3.053\right)$ at $(\mathrm{t}=5.043, \mathrm{P}=0.000)$

d. Diarrhea and its management: There were significant difference in the pre - training scores $\left(\overline{x_{1}}=14.632\right.$, $\left.S_{1}=8.055\right)$ and post - training scores $\left(\overline{x_{2}}=19.921\right.$, $\left.S_{2}=3.612\right)$ at $\left.\mathrm{t}=-3.693, \mathrm{P}=0.000\right)$. e. Overall scores or combined scores in Gboko LGA: There were significant difference in the pre - training scores $\left(\overline{x_{1}}=136.684, S_{1}=37.370\right)$ and post - training scores $\left(\overline{x_{2}}=177.895, S_{2}=14.469\right)$ at $(\mathrm{t}=6.783, \mathrm{P}=$ $0.000)$ see table 1 and 2

This results strongly indicates that the teaching intervention has improve scores and hence the knowledge of the Primary Health care Workers on how to manage childhood illnesses in all topics and on the overall performance in Gboko LGA.

Table 1: Sample statistics and mean percentage response for Gboko study

\begin{tabular}{clcccccc}
\hline Topics & & Total score & N & Mean $(\bar{X})$ & SD $($ S $)$ & SEM & Mean \% response \\
\hline 1 & Pre / 90 & 2425 & 38 & 63.8158 & 15.90148 & 2.57956 & 71 \\
1 & Post / 90 & 3070 & 38 & 80.8947 & 8.75427 & 1.42013 & 90 \\
2 & Pre / 62 & 1629 & 38 & 42.8684 & 13.34606 & 2.16502 & 69 \\
2 & Post /62 & 2122 & 38 & 55.8421 & 4.39611 & .71314 & 90 \\
3 & Pre/ 27 & 584 & 38 & 15.3684 & 6.49083 & 1.05295 & 57 \\
3 & Post /27 & 807 & 38 & 21.2368 & 3.05299 & .49526 & 79 \\
4 & Pre/24 & 556 & 38 & 14.6316 & 8.05529 & 1.30674 & 61 \\
4 & Post /24 & 757 & 38 & 19.9211 & 3.61215 & .58597 & 83 \\
Overall & Pre / 203 & 5194 & 38 & 136.6842 & 37.37762 & 6.06345 & 67 \\
score & Post/ 203 & 6760 & 38 & 177.8947 & 14.46859 & 2.34711 & 88 \\
\hline
\end{tabular}

1. Malaria \& its Management; 2. How to recognize severe illness in children First Aid Management \& Referral;

3. Management of Acute Respiratory Tract Infections \& Other Childhood illnesses; 4. Diarrhoea \& its management especially in children; SD=Standard Deviation; SEM=Standard Error of Mean

Table 2: Paired sample statistics and t- test for Gboko study

\begin{tabular}{ccccccc}
\hline Topics & & Mean $(\bar{X})$ & SD $(\mathrm{S})$ & $\mathrm{t}$ & Df & Sig. (2-tailed) \\
\hline 1 & Pre - Post & -17.07895 & 2.94464 & -5.800 & 74 & .000 \\
2 & Pre - Post & -12.97368 & 2.27945 & -5.692 & 74 & .000 \\
3 & Pre - Post & -5.86842 & 1.16361 & -5.043 & 74 & .000 \\
4 & Pre - Post & -5.28947 & 1.43211 & -3.693 & 74 & .000 \\
Overall score & Pre - Post & -41.21053 & 6.07572 & -6.783 & 74 & .000 \\
\hline
\end{tabular}

1. Malaria \& its Management; 2. How to recognize severe illness in children First Aid Management \& Referral; 3. Management of Acute Respiratory Tract Infections \& Other Childhood illnesses; 4. Diarrhoea \& its management especially in children; $\mathrm{SD}=\mathrm{Standard}$ Deviation

\section{DISCUSSION}

From the biodata, it was observed that over $80 \%$ of participants were experienced Health Workers and all Health Workers in this study could read and write in English. Also, over $80 \%$ of participants were adults who were married and about $79 \%$ of them have children as such most of them might had personal encounter with the disease condition affecting children in this study. As result, almost all of the Health Workers had no difficulty in understanding the training that were giving to them

It has been reported that, in developing countries current treatment levels are unacceptably low that:

(a) only $39 \%$ of children receive correct treatment for diarrhea [20].

(b) Only $30 \%$ of children with suspected pneumonia receive an antibiotic [20].

(c) Less than $20 \%$ of children with fever have test for malaria and receive correct treatment for malaria [21]. 
(d) Poor and disadvantaged children at community level are at even greater risk [21]

This training/assessment exercise was carried out in order to improve the quality of health services given to children with the above illness at the community level. Our statistical analysis of results strongly indicate that the teaching intervention have significantly improved the knowledge of the primary health care workers on how to manage childhood illness in all topics and the overall performance in Gboko LGA. A recent review by the Child Health Epidemiological Reference Group (CHERG) estimate that:

(a) Training of health workers on community management of all cases of childhood pneumonia could result in a $70 \%$ reduction in mortality from pneumonia in children less than 5 years of age [22].

(b) Training of health workers on community case management of malaria can reduce the overall and malaria specific under five mortality by $40-60 \%$ respectively; and severe malaria morbidity by $53 \%[23,24]$.

(c) Oral rehydration salt solution (ORS) and zinc are effective against diarrhea mortality in home and community setting and ORS is estimated to prevent $70-90 \%$ death due to acute watery diarrhea at home and community level [25] and Zinc is estimated to decrease diarrhea mortality by $11.5 \%$ [26].

From our study, it was observed that training of community health workers in Gboko LGA has improved their knowledge on how to manage Malaria illness in children by 90\%, Acute Respiratory Tract infection and other childhood illnesses by $79 \%$ and Diarrhea and its management by $83 \%$. On how to recognize severe illnesses and cases of treatment failure in children, first aid management and referral, there was $90 \%$ improvement in health workers knowledge, and on the overall result or combined scores there was $88 \%$ improvement.

In conclusion, the result from this study strongly indicates that training of primary health care workers on integrated community case management of childhood illnesses in north-west district of Benue state; Nigeria has greatly improved their knowledge on how to manage childhood illnesses. This study is also in line with UNICEF, WHO and other Partners who are supporting the training of community health workers in other to improve their knowledge on integrated community case management of childhood illnesses and hence reduction in mortality and morbidity of children under 5 years of age.

Acknowledgement. We wish to acknowledge the presidential initiative fund Benue State University Makurdi who sponsored the study. We also wish to acknowledge Mr. John Iordye Aju, Mr Ayoo Martins Msughter and late Mr. Michael Demawa who assisted in organizing the study.

\section{REFERENCES}

1. George A., Meno Eti EP, Rivara Montel, Reges C.H., Marsh D.R., (2008) Community case management of childhood illness in Nicaragua: transforming Health System in underserved Rural Areas: Journal of healthcare for the poor and underserved vol. 20 2008, pp 99-115.

2. Yeboah-Anxwi K, Pilingana P., Maclenod W. B., Senrau K., Siazeele k., Kalesh P. et al 2010. Community case management of fever due to Malaria and Pneumonia in children under five in Zambia. A cluster randomized controlled trials PLoS Medicine Vol 7. No. 9, 2010.

3. Mark Young, Wolthern C., Marsh D.R., Hammamy D., 2012. WHO/UNICEF, JOINT STATEMENT on integrated community case management (ICCM). An equity focused strategy to improve access to essential treatment services for children, American Journal of tropical Medicine and Hygiene 87 (suppl.) 2012, 6 - 10.

4. Federal Republic of Nigeria National Malaria strategic plan 2014 - 2020 published by the federal ministry of health in 2013.

5. Charyeva Z, Cannon M. Oguntunde O., Magashi Garba A, (2013) Reducing the burden of diarrhea among children under five years old: Lessons learned from ORS therapy corner programme 
implementation in Nigeria. Journal of health population and nutrition 2013, 34. 4

6. (https://www.unicef.org/Nigeria/media 2364.html)

7. Rudan I., Tomaskoric L. Boschi-Pinto C. and Campbell H. 2004 Global estimate of the incidence of clinical pneumonia among children under five years of age. Bulletin of World Health organization p3 (12): 895-903.

8. William B.G., Gowns E., Boshi-Pinto C., Bryce J. and Dyere 2002. Estimates of worldwide distribution of child death from Acute respiratory infections, Lancet infectious diseases 2 (1): 25 -32.

9. World lung foundation 2010 four million deaths each year caused by Acute respiratory infections, New Atlas Details Pandemic www.worldlungfoundatiion.org/ht/display/releasedet ails/12/503/

10. Acharya D., Prassanna K.S. Nair S. and Rao R. S. 2003 Acute Respiratory infections in children: a Community Based longitudinal study in south India; India Journal of Public Health 47 (1): 1-3.

11. Lucy Eberechukwu Y.I. and Tochi Ada U.O. 2015, burden of acute respiratory tract infections as seen in University of Port-Harcourt Teaching Hospital, Nigeria Journal of US-China Medical Science 12, 158-162.

12. National Population Commission (NPC) Nigeria and ICF international 2014, Nigeria Demographic and Health survey 2013 Abuja, Nigeria and Rockville Maryland USH: NPC and ICF International.

13. Adulraheem I.S., Olapipo M.R, and Amodu M.O. 2012 "Primary Health care services in Nigeria Journal of Public Health and epidemiology vol 4 (1) 5 $-13$.

14. Amee Tser (2013) The dynamics of Benue state population 1963-2016, $1^{\text {st }}$ Edition Micro Teacher and Associates, High Level, Makurdi. 2013, 38-74.

15. Caring for the sick child in the community training course for Community Health Worker WHO 2011

16. Federal Ministry of Health national Malaria Control Programme Abuja, Nigeria: Module 2: Case management of Malaria at the Primary health Care Centre Trainee content.
17. National guideline for diagnosis and Treatment of Malaria (2011) Federal Ministry of health, National Malaria and Vector control Division Abuja - Nigeria march 2011.

18. MacGill Markus (2015) Diarrhoea causes symptoms and treatment Medical News today retrieved from http://www.medicalnewstoday.com/articles/158634.p hp.

19. Wagas and Sellen Daniel (2011) Zinc Supplement in the Management of diarrhoea in the Management of diarrhoea http://www.WHO.int/clena/tittles/bbce/zincdiarrhoea/ $\underline{\text { en }}$

20. United Nations Children Fund, the state of the world's Children 2012: Children in an urban world UNICEF, New York 2012 p.99.

21. Roll Back Malaria Partnership, A decade of partnership and result: Progress and impact series report 7 Geneva September 2011.

22. Theodaratou Evropi et al;Al-Jilaihawi S., Woodward F., Ferguson J., Jhag A., Ballet M. Kolae I. et al (2010). The Effect of Case Management of Childhood Pneumonia mortality in developing countries; international Journal of Epidemiology vol. 39, 2010, pp. 1156-1171.

23. Kidane G, and R.H. Morrow, (2010). Teaching Mothers to provide home Treatment of Malaria in Tigray, Ethiopia: A randomized trial lancet, vol 356 no. 9229, 2000, pp550-555.

24. Sirima S.B., Konate A. Tiono A. B., Convelbo N.,Cousens N., Consens S., Pagmoni F. (2003) Early treatment of childhood fever, W.A. pre-packaged antimalaria drugs in the home reduces severe malaria morbidity in Burkina-Faso Tropical Medicine International Health 8, 133-139

25. Munos M.K., Fischer-Walker cl Black RE (2010) The effect of oral rehydration solution and recommended home fluids on diarrhoea mortality International Journal of Epidemiology 39 175-182

26. Fischer-Walker, CL Black Re, (2010) zinc for the treatment of diarrhoea effect on diarrhoea morbidity and incidence of future episodes international Journal of Epidemiology 39: 163-169. 